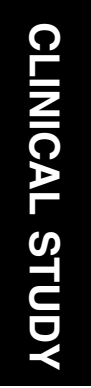

${ }^{1}$ Cecil G. Sheps Center for Health Services Research, Eshelman School of Pharmacy, University of North Carolina, Chapel Hill, North Carolina, USA

${ }^{2}$ Division of Pharmaceutical Outcomes and Policy, Eshelman School of Pharmacy, University of North Carolina, Chapel Hill, North Carolina, USA

${ }^{3}$ Department of International Health, Bloomberg School of Public Health, Johns Hopkins University, Baltimore, Maryland, USA

${ }^{4}$ Department of Ophthalmology, School of Medicine, Johns

Hopkins University and University of Maryland School of Medicine, Baltimore, Maryland, USA

${ }^{5}$ Department of Ophthalmology, School of Medicine, University of North Carolina, Chapel Hill, North Carolina, USA

${ }^{6}$ Alcon Research Ltd, Fort Worth, Texas, USA

${ }^{7}$ Department of Health Behavior and Health Education, School of Public Health, University of North Carolina, Chapel Hill, North Carolina, USA

${ }^{8}$ Department of Psychology, University of North Carolina, Chapel Hill, North Carolina, USA

${ }^{9}$ Department of Ophthalmology, Emory University, Atlanta,

Georgia, USA

Correspondence: B Sleath, Division of Pharmaceutical Outcomes and Policy,

Eshelman School of Pharmacy, University of North Carolina, CB \#7590, Chapel Hill, North Carolina 27599-7590, USA.

Tel: + 19199668969 ;

Fax: + 19199668486.

E-mail: betsy_sleath@unc.edu

Received: 9 August 2008 Accepted in revised form: 9 June 2009

Published online: 17 July 2009

\section{Development of an instrument to measure glaucoma medication self- efficacy and outcome expectations}

B Sleath ${ }^{1,2}$, SJ Blalock², A Robin ${ }^{3,4}$, ME Hartnett ${ }^{5}$, D Covert ${ }^{6}$, B DeVellis ${ }^{7,8}$ and A Giangiacomo ${ }^{9}$

\begin{abstract}
Purpose The purpose of this study was to develop and evaluate the psychometric properties of (a) a glaucoma medication selfefficacy scale and (b) a glaucoma outcome expectations scale.

Patients and Methods Two instruments were developed: a glaucoma medication self-

Conclusions Eye care providers and researchers can use these scales to identify patients with low self-efficacy in using their glaucoma medications and patients who do not believe that following their eye care providers' advice can help their vision. Eye (2010) 24, 624-631; doi:10.1038/eye.2009.174; published online 17 July 2009
\end{abstract} efficacy scale and a glaucoma outcome expectations scale. Packets containing (a) the instruments and patient demographic questions and (b) a letter explaining the study were distributed to 225 glaucoma patients from three ophthalmology practices between August and December 2007. The instrument was completed by 191 patients for a response rate of $85 \%$. Principal components factor analysis with a varimax rotation and Cronbach's $\alpha$ reliability were used to analyse the data. To assess discriminant validity, we administered the scales and two self-reported measures of adherence in a separate sample of 43 glaucoma patients who were currently using at least one glaucoma medication.

Results Our results yielded a 21-item self-efficacy in overcoming barriers that might interfere with the use of glaucoma medications scale, a 14-item self-efficacy in carrying out specific tasks required to use eye drops correctly scale, and a four-item glaucoma outcome expectations scale. Results of the Cronbach's $\alpha$ reliability indicated that the scales are internally consistent. The selfefficacy scales were both significantly associated with two patient self-reported measures of glaucoma medication adherence, which show discriminant validity.
Keywords: glaucoma; self-efficacy; outcome; expectations; adherence

\section{Introduction}

Between 9 and $12 \%$ of all blindness in the United States is attributed to glaucoma. ${ }^{1}$ The primary goal of glaucoma treatment is to reduce intraocular pressure. ${ }^{2,3}$ Using available glaucoma medications can significantly lower intraocular pressure and reduce the progression of glaucoma. ${ }^{4,5}$ However, despite the availability of effective medications, nonadherence and lack of persistence in using prescribed therapy is a significant problem. ${ }^{6}$ Approximately $50 \%$ of the individuals who start on glaucoma medications discontinue them within 6 months. ${ }^{7,8}$

Further, even when patients attempt to adhere to their eye drop medications, research has shown that patient performance during eye drop administration is poor. In a recent study, 140 experienced glaucoma patients were video taped when instilling their eye drops. ${ }^{9}$ This study found that $18 \%$ of patients missed their eye when administering their drops, only $60 \%$ of patients instilled the correct number of drops, and $65 \%$ of patients contaminated the bottle by touching it to the eye. Another study of 324 
glaucoma patients found that $20 \%$ of patients stated that no one had shown them how to use their glaucoma medications. $^{10}$

Social cognitive theory is a promising theoretical framework for understanding glaucoma patients' medication adherence and eye drop technique. ${ }^{11}$ Self-efficacy is one of the key constructs in social cognitive theory. ${ }^{12}$ Self-efficacy is defined as individuals' personal beliefs regarding their capabilities to carry out a specific task to achieve a desired outcome. ${ }^{13,14}$ According to social cognitive theory, if individuals have higher self-efficacy or self-confidence that they can perform a certain behaviour, such as taking eye drops, they are more likely to undertake the behaviour.

Outcome expectations is another key construct in social cognitive theory. ${ }^{11}$ Outcome expectations are whether an individual believes that a certain behaviour (e.g. taking eye drops) will have a positive impact on a health condition (e.g. glaucoma). ${ }^{11}$ According to social cognitive theory, if an individual believes that taking eye drops will help their glaucoma, then that individual is more likely to take the eye drops than someone who does not believe that they are helpful. Studies in HIV, diabetes, asthma, and depression have found positive associations between self-efficacy and (a) medication adherence and (b) other disease-specific self-management behaviours. ${ }^{15-21}$ Very little work has examined how patient outcome expectations impact medication adherence and disease-specific self-management behaviours. $^{22}$

Instruments to assess self-efficacy and outcome expectations have been developed and used in various chronic conditions, such as hypertension, asthma, osteoporosis, and arthritis ${ }^{22-30}$, but to our knowledge, no instrument exists for measuring self-efficacy in relation to the use of glaucoma medications. Therefore, the purpose of this study was to develop and evaluate the psychometric properties of (a) a glaucoma medication self-efficacy scale and (b) a glaucoma outcome expectations scale.

\section{Methods}

\section{Questionnaire development}

Two instruments were developed: a glaucoma medication self-efficacy scale and a glaucoma outcome expectations scale. The self-efficacy scale that was developed was modelled after the medication selfefficacy scale in hypertensive patients scale because glaucoma is similar to hypertension in that it is an asymptomatic and chronic condition. ${ }^{23}$ We modified the scale to be appropriate for glaucoma patients and eye drop use with input from four practicing ophthalmologists, 10 glaucoma patients taking glaucoma eye drops, the peer-reviewed literature, and results from our earlier work, ${ }^{31}$ in which we asked over 300 glaucoma patients from four practices about their problems and concerns in using their glaucoma medications. ${ }^{32-35}$ The main changes that were made to the medication self-efficacy scale in hypertensive patients scale were that the questions asking about specific side effects to anti-hypertensive medications were modified to reflect specific side effects of glaucoma medications. Also, we added a series of questions focusing on ability to use eye drops correctly. ${ }^{31,32}$ Therefore, we developed a questionnaire with two proposed dimensions (one focusing on overcoming barriers to eye drop use in general and one focusing on the patient's ability to use eye drops correctly). The glaucoma outcome expectations instrument was modelled after an outcome expectations scale from asthma, but we modified the questions to make them appropriate for glaucoma patients. ${ }^{22}$

The final questionnaire that patients completed included a total of 43 items designed to assess (a) selfefficacy in overcoming barriers that might interfere with the use of glaucoma medications (22 items), (b) selfefficacy in carrying out specific tasks required to use eye drops correctly (15 items), and (c) outcome expectations associated with glaucoma treatment (6 items). The response categories for the self-efficacy items were not at all confident, somewhat confident, very confident, and does not apply. The response options for the outcome expectations items (questions asking how much do you think it will help...') were recorded on a 9-point Likert scale ranging from 'not at all' to 'somewhat' to 'extremely'. The survey also collected information on patient demographics.

\section{Data collection procedures}

The research project was approved by the University of North Carolina Institutional Review Board. Between August and December of 2007, three ophthalmology practices distributed packets to glaucoma patients who agreed to complete the questionnaire. The packet contained a letter explaining the study from the principal investigator with a contact number to call, a questionnaire, and an envelope with prepaid postage, so that the patient could send the survey back directly and anonymously to the principal investigator. Two hundred and twenty-five packets were distributed and 191 patients returned the survey, which gave us a response rate of $85 \%$.

\section{Analysis}

Three separate principal components factor analyses with varimax rotation were performed. Varimax is the 
most common type of rotation used when performing factor analysis. ${ }^{36,37}$ It maintains the independence of the underlying factors and, therefore, is simpler to interpret than procedures that allow the factors to be correlated. In the factor analyses, the mean score was substituted for items with missing values. Factor loadings, eigenvalues, and scree plots were examined to determine the number of factors to extract. Items with loadings above 0.40 were retained. ${ }^{36}$ Factor loadings indicate the correlation of an item with an underlying factor. Correlations above 0.30 or 0.40 are generally considered as meaningful. ${ }^{36,37}$ Once the number of factors were identified, scale scores were computed by summing the unweighted responses across items. Reliability of the resulting scales was assessed using Cronbach's $\alpha$.

The bivariate relationships between the independent variables and the self-efficacy and outcome expectations measures were examined using $t$-tests and correlations. The independent variables included patient age, gender, race, years of education, length of time with glaucoma, in which eye the patient has glaucoma, how many glaucoma medications the patient uses, and how often the patient administers their own eye drops. Table 1 illustrates the response categories for the independent variables.

Once we completed development of the scales, we conducted a pilot study to assess the discriminant validity of the scales by distributing packets with the newly developed scales and two self-report measures of adherence $^{38,39}$ to 60 glaucoma patients who were using at least one glaucoma medication. One of the self-report adherence measures assesses medication adherence over the earlier month using a four-item validated measure ranging from zero (low) to four (high) non-adherence. ${ }^{38}$ This measure has shown sensitivity to change in randomized trials. ${ }^{38}$ The Morisky measure can also be dichotomized into those individuals who report any nonadherence versus those who report being 100\% adherent. The other measure of self-reported adherence used was a visual analogue scale, which asks patients to put a line on a 10-cm scale indicating how much of the time they use all of their glaucoma medications exactly as directed (range is from $0=$ none of the time to $10=$ all of the time). ${ }^{39-43}$ The visual analogue scale has strong validity and reliability. ${ }^{39-43}$ Forty-three packets were returned for a response rate of $72 \%$.

\section{Results}

Table 1 presents the patient characteristics. Forty-four percent of the patients were female and approximately $24 \%$ were non-White. Patients ranged in age from 18 to 94 and the average patient age was 66.5 years (standard deviation $=13.1$ ). The majority of patients
Table 1 Patient characteristics $(N=191)$

\begin{tabular}{|c|c|}
\hline & Percent (N) \\
\hline \multicolumn{2}{|l|}{ Gender } \\
\hline Male & $46.6(89)$ \\
\hline Female & $44.0(84)$ \\
\hline Missing & $9.4(18)$ \\
\hline \multicolumn{2}{|l|}{ Race } \\
\hline White & $69.1(132)$ \\
\hline Non-White & $23.6(45)$ \\
\hline Missing & $7.3(14)$ \\
\hline \multicolumn{2}{|l|}{ How long has had glaucoma } \\
\hline$<6$ months & $2.6(5)$ \\
\hline 6 months to $<1$ year & $3.7(7)$ \\
\hline 1 to 2 years & $6.8(13)$ \\
\hline$>2$ years to $<5$ years & $14.7(28)$ \\
\hline 5 years or more & $65.9(126)$ \\
\hline Missing & $6.3(12)$ \\
\hline \multicolumn{2}{|l|}{ In which eye has glaucoma } \\
\hline Right & $8.9(17)$ \\
\hline Left & $8.9(17)$ \\
\hline Both & $75.9(145)$ \\
\hline Missing & $6.3(12)$ \\
\hline \multicolumn{2}{|c|}{ How many glaucoma medications patient uses } \\
\hline One & $33.5(64)$ \\
\hline Two & $35.1(67)$ \\
\hline Three & $16.8(32)$ \\
\hline More than three & $9.9(19)$ \\
\hline Missing & $4.7(9)$ \\
\hline \multicolumn{2}{|c|}{ How often patient administers own glaucoma medications } \\
\hline Most of the time & $80.6(154)$ \\
\hline Some of the time & $9.9(19)$ \\
\hline Never & $1.0(2)$ \\
\hline \multirow[t]{3}{*}{ Missing } & $2.1(4)$ \\
\hline & $6.3(12)$ \\
\hline & $\begin{array}{c}\text { Range; Mean } \\
\text { (standard deviation) }\end{array}$ \\
\hline Age & $18-94 ; 66.5,(13.1)$ \\
\hline Years of education & $2-30 ; 14.91(4.06)$ \\
\hline
\end{tabular}

had glaucoma in both eyes and $66 \%$ of the patients had glaucoma for 5 years or more.

\section{Self-efficacy in overcoming barriers that might interfere with the use of glaucoma medications}

One of the 22 items that was administered to assess selfefficacy in overcoming barriers that might interfere with the use of glaucoma medications was dropped from the analysis because 100 patients chose 'does not apply' for their answer. The question asked was about confidence in taking glaucoma medications at work. It makes sense that the question did not apply to many of the 
Table 2 Results of principal components analysis with varimax rotation for self-efficacy in overcoming barriers that might interfere with the use of glaucoma medications $(N=191)$

How confident are you that you can take your glaucoma medications... Factor loadings

When you are busy at home?

When there is no one to remind you?

When you worry about using them the rest of your life?

When they cause some side effects?

When they cost a lot of money?

When you come home late from work or some other activity?

When you do not have symptoms?

When you are with family members?

When you are in a public place?

When you are afraid of becoming dependent on them?

When you are afraid they may make your eyes red?

When the time to use them is between your meals?

When you feel you do not need them?

When you are travelling?

When you have to use them more than once a day?

If they sometimes make your eyes burn or sting?

When you have other medications to take?

When you feel well?

If they sometimes make you bothered by feelings of stickiness or crustiness in or around your eyes?

If they sometimes make your eyes dry?

participating individuals because the mean age of our sample was 66.5 years and most likely many patients were retired. A principal components analysis of the remaining 21 items yielded one interpretable factor explaining $33.35 \%$ of the total variance. Table 2 presents the factor loadings for this one-factor solution. All items were loaded at 0.40 or higher. The resulting 21 -item factor had a Cronbach's $\alpha$ reliability of 0.90 . Scores ranged from 27 to 63 (mean $=57.32$, standard deviation $=5.68$ ).

\section{Self-efficacy in carrying out specific tasks required to use eye drops correctly}

A principal components analysis with a varimax rotation of the 15 items yielded two interpretable factors. One of the items, which asked about confidence in using eye drops correctly, was dropped from the analysis because it ambiguously loaded on both factors. The principal components analysis was then reran with the 14 items and a two-factor solution was obtained that explained $49.15 \%$ of the total variance. Table 3 presents the factor loadings for the two-factor solution. All items were loaded at 0.40 or higher.

One factor had eight items, which focused on confidence in using eye drops in general (being able to open the bottle, being able to get refills, etc.), and the other factor had six items, which focused on the ability to get the eye drops correctly in the eye (being able to angle their head correctly, being able to get the right amount in the eye, etc.). The resulting eight-item factor had a Cronbach's $\alpha$ of 0.76 , with scores ranging from 10 to 24 (mean $=22.38$, standard deviation $=2.11$ ). The resulting six-item scale had a Cronbach's $\alpha$ of 0.87 , with scores ranging from 7.91 to 18 (mean $=16.34$, standard deviation $=2.17$ ).

\section{Outcome expectations}

Inspection of inter-item correlations revealed that several of the six outcome expectations items were highly correlated. In addition, a couple of patients stated that the items seemed repetitive when asked for their input into the survey's development. For example, the item 'How much do you think it will help your glaucoma if you follow your eye doctor's instructions exactly?' correlated at 0.91 with the item 'How much do you think it will help your glaucoma if you use your eye drops regularly?'. In addition, the item 'How much do you think it will help your vision if you use your eye drops regularly?' correlated 0.95 with the item 'How much do you think it will help your vision if you follow your eye doctor's instructions exactly?'. Therefore, only one of each of these sets of items was included in the factor analysis. The items not included were 'How much do you think it will help your vision if you follow your eye doctor's instructions exactly?' and 'How much do you think it will help your glaucoma if you follow your eye doctor's instructions exactly?'. 
Table 3 Results of principal components analysis with varimax rotation for self-efficacy in carrying out specific tasks required to use eye drops correctly $(N=191)$

\begin{tabular}{|c|c|c|}
\hline How confident are you that you can carry out the following tasks... & $\begin{array}{l}\text { Factor } 1 \\
\text { loadings }\end{array}$ & $\begin{array}{l}\text { Factor } 2 \\
\text { loadings }\end{array}$ \\
\hline Squeezing your eye drop bottle(s)? & 0.73 & 0.05 \\
\hline Getting the medication drop(s) in your eye? & 0.81 & 0.13 \\
\hline Using your eye drops without having someone help you? & 0.46 & 0.25 \\
\hline Consistently getting the right amount of eye drop medication in your eye each time you use it? & 0.82 & 0.23 \\
\hline Correctly angling your head to accurately apply the eye drops? & 0.85 & 0.06 \\
\hline $\begin{array}{l}\text { Delivering the required amount of your eye drops to the eye without missing or applying too much } \\
\text { medication? }\end{array}$ & 0.83 & \\
\hline Getting refills for your glaucoma medications before you run out? & 0.12 & 0.65 \\
\hline Filling your prescriptions for glaucoma medications whatever the cost? & 0.14 & 0.57 \\
\hline Making using your glaucoma medications part of your routine? & 0.15 & 0.75 \\
\hline Always remembering to use your glaucoma medications? & 0.20 & 0.67 \\
\hline Using your glaucoma medications for the rest of your life? & 0.11 & 0.67 \\
\hline Opening the eye drop bottle? & 0.28 & 0.62 \\
\hline Getting the plastic seal off a new eye drop bottle? & 0.17 & 0.42 \\
\hline Using your eye drops with someone helping you? & -0.20 & 0.48 \\
\hline
\end{tabular}

Table 4 Results of principal components analysis for outcome expectations in using glaucoma medications $(N=191)$

\begin{tabular}{lr}
\hline & Factor 1 loadings \\
\hline How much do you think it will help your glaucoma to come to your appointments with your eye doctor? & 0.77 \\
How much do you think it will help your glaucoma if you use your eye drops regularly? & 0.81 \\
How much do you think it will help your vision to come to these appointments with your eye doctor? & 0.89 \\
How much do you think it will help your vision if you use your eye drops regularly? & 0.81 \\
\hline
\end{tabular}

A principal components analysis of the four items yielded a one-factor solution that explained $66.98 \%$ of the total variance. Table 4 presents the factor loadings. All items were loaded at 0.40 or higher. The resulting factor had a Cronbach's $\alpha$ reliability of 0.83 . Scores ranged from 4 to $36($ mean $=33.83$, standard deviation $=4.25)$.

\section{Bivariate relationships}

Individuals who rated their health more poorly had lower self-efficacy in getting their drops in their eyes correctly (Pearson correlation $=-0.19, P=0.013$ ). Individuals who had glaucoma longer reported higher self-efficacy in getting their drops in their eyes correctly (Pearson correlation $=0.20, P=0.006$ ). Individuals who always administered their eye drops themselves reported higher self-efficacy in overcoming barriers that might interfere with the use of glaucoma medications ( $t$ test $=2.28, P=0.035$ ) and higher self-efficacy in getting their drops in their eyes correctly ( $t$-test $=2.23, P=0.027$ ).

Although the findings were not statistically significant, we did find that African-American patients tended to have lower mean scores $(2.69$ (standard deviation $=0.28$ ) compared with 2.76 (standard deviation $=0.24)$ ) than White patients on the self-efficacy in overcoming barriers that might interfere with the use of glaucoma medications scale. African Americans had similar mean scores as Whites (2.76 (standard deviation $=0.27$ ) compared with 2.77 (standard deviation $=0.26$ ) ) on the self-efficacy in carrying out specific tasks required to use eye drops correctly scale. Although not significant, African-American patients had higher mean scores than Whites $(8.63$ (standard deviation $=0.75)$ compared with 8.39 (standard deviation $=1.19$ ) ) on the outcome expectations scale. Future research should examine whether racial differences in patients' self-efficacy in using glaucoma medications and patients' glaucoma outcome expectations exist using larger sample sizes. It is important to examine racial differences in self-efficacy and outcome expectations because glaucoma and blindness from glaucoma are higher in Blacks than Whites and their disease is frequently more advanced at time of diagnosis. ${ }^{4-46}$

\section{Discriminant validity}

On the Morisky four-item adherence measure, 30.2\% of the patients indicated some non-adherence to their glaucoma medications in the last 4 weeks. On the visual analogue scale, patient scores ranged from 4.8 to $10 \mathrm{~cm}$ 
(mean 9.24, standard deviation $=1.05$ ). The self-efficacy in overcoming barriers that might interfere with the use of glaucoma medications correlates significantly with the Morisky four-item adherence measure (Pearson correlation coefficient $=-0.33, P=0.042)$ and the visual analogue scale measure (Pearson correlation coefficient $=0.32, P=0.037$ ). The self-efficacy in carrying out specific tasks required to use eye drops correctly scale also correlated significantly with the Morisky four-item adherence measure (Pearson correlation coefficient $=-0.39, P=0.014)$ and the visual analogue scale measure (Pearson correlation coefficient $=0.41$, $P=0.007)$. Patients with higher self-efficacy were significantly more likely to be adherent to their glaucoma medications. When using the dichotomous Morisky self-report adherence measure (100\% adherence versus patient reports some non-adherence), the non-adherent patients had significantly lower mean scores than adherent patients on both the self-efficacy in overcoming barriers that might interfere with the use of glaucoma medications scale (mean score of adherent patients = 2.78 (standard deviation $=0.27$ ) and mean score of non-adherent patients $=2.57$ (standard deviation $=0.29$ ); $t$-test $=2.09, P=0.04)$ and the self-efficacy in carrying out tasks required to use eye drops correctly scale (mean score of adherent patients $=2.77$ (standard deviation $=0.25$ ) and mean score of non-adherent patients $=2.51$ (standard deviation $=0.43$ ); $t$-test $=2.45$, $P=0.02)$.

The outcome expectations scale did not correlate significantly with either adherence measures. However, when using the dichotomous Morisky self-report adherence measure (100\% adherence versus patient reports some non-adherence), non-adherent patients had lower mean scores on the outcome expectations scale $(6.82$ (standard deviation $=0.84))$ than adherent patients (7.06 (standard deviation $=0.70)$ ). Although the results were not statistically significant, there is a trend towards non-adherent patients having lower outcome expectations than adherent patients.

\section{Discussion}

This study reports on the development and evaluation of a glaucoma medication self-efficacy scale and a glaucoma outcome expectations scale. Self-efficacy and outcome expectations are important concepts because they can potentially explain adherence behaviour and patient eye drop technique. Our results yielded a 21-item selfefficacy in overcoming barriers that might interfere with the use of glaucoma medications scale, a 14-item selfefficacy in carrying out specific tasks required to use eye drops correctly scale, and a four-item glaucoma outcome expectations scale. The results of the Cronbach's $\alpha$ reliability indicated that the scales are internally consistent. To our knowledge, these are the first selfefficacy and outcome expectations scales that have been developed for glaucoma patients. These scales have many potential applications for clinical practice and research.

The self-efficacy in overcoming barriers that might interfere with the use of glaucoma medications scale can be used by eye care providers to detect when patients do not feel confident taking their glaucoma medications under certain circumstances (e.g. when they cause side effects, when patients are busy). Providers could then use patient responses to help them problem solve and to boost patient confidence in taking eye drops under these reported circumstances.

The self-efficacy in carrying out specific tasks required to use eye drops correctly scale can be used by eye care providers to screen for whether patients report a lack of confidence in certain aspects of using their eye drops (e.g. getting the drop of medication in the eye, squeezing the eye drop bottle). Providers could use these results to identify patients who need additional teaching and modelling on how to correctly use their eye drops.

Both of our developed self-efficacy scales, the self-efficacy for overcoming barriers that might interfere with the use of glaucoma medications scale and the self-efficacy in carrying out tasks required to use eye drops correctly scale, were found to be significantly associated with patient adherence. Patients who had more self-efficacy or confidence in using their glaucoma medications were more adherent. The developed selfefficacy scales can be used to screen for patients who have low self-efficacy or confidence in using their glaucoma medications, so that providers can educate and attempt to improve self-efficacy and hopefully medication adherence.

The outcome expectations scale can be used by eye care providers to assess whether patients believe that taking their eye drops regularly and keeping eye appointments will help their glaucoma and vision. If a patient does not believe that any of these factors may impact their glaucoma and vision, their eye care provider can then educate them about how these factors can potentially impact their glaucoma and vision. Earlier research indicates that patients may not be receiving adequate information about their glaucoma. ${ }^{10,47}$ Eye care providers should make sure to educate patients about the importance of using eye drops regularly and how glaucoma can lead to blindness.

The factor analysis of our glaucoma medication selfefficacy scale in overcoming barriers that might interfere with the use of glaucoma medication had one factor, which is identical to the medication self-efficacy in hypertensive patients scale, which it was modelled 
after. $^{23}$ As our study focused on glaucoma patients and the use of eye drops, we added a self-efficacy scale in carrying out specific tasks required to use eye drops correctly. This scale ended up having a two-factor solution, in which one factor focused on confidence in using eye drops in general and one focused on the ability to get the eye drops correctly in the eye. The factor analysis of our outcome expectations scale had one factor, which is identical to the asthma outcome expectations scale, which it was modelled after. ${ }^{22}$

The self-efficacy and outcome expectations scales could also be used in glaucoma research. First, they could be administered to examine how self-efficacy and outcome expectations are related to patient outcomes such as adherence or intraocular pressure. Second, if intervention studies are conducted to either educate patients about their glaucoma, improve their adherence, or improve their eye drop technique, the scales could be given pre- and post-intervention, so that researchers could examine the impact of their interventions on self-efficacy and outcome expectations.

Individuals who rated their health more poorly had worse self-efficacy in getting their eye drops in their eyes correctly. Eye care providers should attempt to ask patients about how their other medical conditions might be impacting their ability to get their eye drops in their eyes correctly. If potential difficulties are then discovered, the eye care provider and patient can strategize on possible solutions (e.g. having someone help the patient administer their drops).

The study has several limitations. First, the clinics did not track the characteristics of those patients who did not respond to the survey. Second, all three of the

participating clinics were located in the southeast, which limits generalizability. Third, we did not assess eye drop technique. Future research should examine whether the self-efficacy and outcome expectations scales that were developed are correlated with glaucoma medication adherence and patient eye drop technique in larger patient samples.

To our knowledge, these are the first self-efficacy and outcome expectation scales that have been developed for glaucoma patients. Eye care providers and researchers can use these scales to identify patients with low self-efficacy in using their glaucoma medications and patients who do not believe that following their eye care providers' advice can help their glaucoma and vision.

\section{References}

1 Glaucoma Research Foundation. Glaucoma Facts and Stat. Available athttp://www.glaucoma.org/learn/facts.html, 2005.
2 Pizzarello L, Abiose A, Ffytche T, Duerksen R, Thulasiraj R, Taylor $\mathrm{H}$ et al. VISION 2020: the right to sight: a global initiative to eliminate avoidable blindness. Arch Ophthalmol 2004; 122(4): 615-620.

3 Gordon MO, Beiser JA, Brandt JD, Heuer DK, Higginbotham EJ, Johnson CA et al. The ocular hypertension treatment study: baseline factors that predict the onset of primary open-angle glaucoma. Arch Ophthalmol 2002; 120(6): 714-720.

4 Higginbotham EJ, Schuman JS, Goldberg I, Gross RL, Van Denburgh AM, Chen K et al. Bimatoprost Study Groups 1 and 2: one-year, randomized study comparing bimatoprost and timolol in glaucoma and ocular hypertension. Arch Ophthalmol 2002; 120: 1286-1293.

5 Camras CB, The United States Latanoprost Study Group. Comparison of latanoprost and timolol in patients with ocular hypertension and glaucoma: a six-month, masked multicenter trial in the United States. Ophthalmology 1996; 103: 138-147.

6 Buller AJ, Connell B, Spencer AF. Compliance: clear communication's critical. Br J Ophthalmol 2005; 89: 137.

7 Nordstrom BL, Friedman DS, Mozaffari E, Quigley HA, Walker AM. Persistence and adherence with topical glaucoma therapy. Am J Ophthalmol 2005; 140(4): 598-606.

8 Schwartz GF, Platt R, Reardon G, Mychaskiw MA. Accounting for restart rates in evaluating persistence with ocular hypotensives. Ophthalmology 2007; 114: 648-652.

9 Robin AL, Stone JL, Sleath B, Covert DW, Cagle GD. An objective evaluation in glaucoma patients of eye-drop instillation using video observations patient surveys. Presentation, American Glaucoma Society Annual Meeting, 2008.

10 Sleath B, Robin A, Byrd J, Covert D, Tudor G. Glaucoma patient receipt of information and instruction on how to use their eye drops. Intl J Pharm Practice 2008; 16: 35-40.

11 Baranowski T, Perry CL, Parcel GS. How individuals, environments, and health behavior interact: social cognitive theory. In: Glanz K, Rimer BK, Lewis FM (eds). Health Behavior and Health Education. John Wiley \& Sons: Hoboken NJ, 2002, pp 165-184.

12 Bandura A. Social Foundation of Thought and Action: A Social Cognitive Theory. Prentice-Hall: Englewood Cliffs NJ, 1986.

13 Bandura A. Human agency in social cognitive theory. Am Psychol 1998; 44(9): 1175-1184.

14 DeVellis BM, DeVellis RF. Self-efficacy and health. In: Baum A and Revenson TA (eds). Handbook of Health Psychology. Lawrence Erlbaum: NY, 2001, pp 235-248.

15 Parsons JT, Rosof E, Mustanski B. Medication adherence mediates the relationship between adherence self-efficacy and biological assessments of HIV health among those with alcohol use disorders. AIDS Behav 2008; 12(1): 95-103.

16 Sarkar U, Fisher L, Schillinger D. Is self-efficacy associated with diabetes self-management across race/ethnicity and health literacy? Diabetes Care 2006; 29(4): 823-829.

17 Burra TA, Chen E, McIntyre RS, Grace SL, Blackmore ER, Stewart DE. Predictors of self-reported antidepressant adherence. Behav Med 2007; 32: 127-134.

18 Skaff MM, Mullan JT, Fisher L, Chesla CA. A contextual model of control beliefs, behavior, and health: Latino and European Americans with Type 2 diabetes. Psychol Health 2003; 18(3): 295-312.

19 Johnson MO, Catez SL, Remien RH, Rotheram-Borus MJ, Morin SF, Charlebois E et al. Theory guided, empirically support avenues for intervention on HIV medication 
non-adherence: findings from the healthy living project. AIDS Patient Care STDs 2003; 17: 645-656.

20 Clark NM, Rakowski W, Wheeler JR, Ostrander LD, Oden S. Development of self-management education for elderly heart patients. Gerontologist 1988; 28(4): 491-494.

21 Bonner S, Zimmerma BJ, Evans D, Irigoyen M, Resnick D, Mellins RB. An individualized intervention to improve asthma management among urban Latino and African-American families. J Asthma 2002; 39: 167-179.

22 Holden G, Wade S, Mitchell H, Ewart C, Islam S. Caretaker expectations and the management of pediatric asthma in the inner city: a scale development study. Soc Work Res 1998; 22: 51-59.

23 Ogedegbe G, Mancuso CA, Allegrante JP, Charlson ME. Development and evaluation of a medication adherence self-efficacy scale in hypertensive African-American patients. J Clin Epidemiol 2003; 56: 520-529.

24 Strecher VJ, DeVellis BM, Becker MH, Rosenstock IM. The role of self-efficacy in achieving health behavior change. Health Educ Q 1986; 13(1): 73-92.

25 Horan Ml, Kim KK, Gendler P, Froman RD, Patel MD. Development and evaluation of the osteoporosis selfefficacy scale. Res Nurs Health 1998; 21(5): 395-403.

26 Lorig K, Chastain RL, Ung E, Shoor S, Holman HR. Development and evaluation of a scale to measure perceived self-efficacy in people with arthritis. Arthritis Rheum 1989; 32(1): 37-44.

27 Tobin DL, Wigal JK, Winder JA, Holroyd KA, Creer TL. The 'asthma self-efficacy scale. Ann Allergy 1987; 59(4): 273-277.

28 Wigal JK, Creer TK, Kotses H. The COPD seld-efficacy scale. Chest 1991; 99(5): 1193-1196.

29 Moens A, Grypdonck MHF, van der Bijl JJ. The development and psychometric testing of an instrument to measure diabetes management self-efficacy in adolescents with type 1 diabetes. Scholarly inquiry for nursing practice. Int J 2001; 15(3): 223-233.

30 Rapley P, Passmore A, Phillips M. Review for the psychometric properties of the diabetes self-efficacy scale: Australian longitudinal study. Nurs Health Sci 2003; 5: 289-297.

31 Day DG, Sharpe ED, Atkinson MJ, Stewart JA, Stewart WC. The clinical validity of the treatment satisfaction survey for intraocular pressure in ocular hypertensive and glaucoma patients. Eye 2006; 20: 583-590.

32 Sleath B, Robin AL, Covert D, Byrd JE, Tudor G, Svarstad B. Patient-reported behavior and problems in using glaucoma medications. Ophthalmology 2006; 113(3): 421-436.
33 Tsai JC, McClure CA, Ramos SE, Schlundt DG, Pichert JW. Compliance barriers in glaucoma: a systematic classification. J Glaucoma 2003; 12(5): 393-398.

34 Taylor SA, Galbraith S, Mills RP. Causes of non-compliance with drug regimens in glaucoma patients: a qualitative study. J Ocul Pharmacol Ther 2002; 18: 401-409.

35 Winfield AJ, Jessiman D, Williams A, Esakowitz L. A study of the causes of non-compliance by patients prescribed eye-drops. BR J Ophthalomol 1990; 74: 477-480.

36 Portney LG, Watkins MP. Foundations of Clinical Research: Applications to Practice. Prentice Hall: New Jersey, 2000.

37 Devellis RG. Scale Development: Theory and Applications. Sage Publications: Newbary Park, 1991.

38 Morisky DE, Green LW, Levine DM. Concurrent and predictive validity of a self-reported measure of medication adherence. Med Care 1986; 24: 67-74.

39 McDowell I, Newell C. Measuring Health: A Guide to Rating Scales and Questionnaires. Oxford University Press: New York, 1996

$40 \mathrm{Nu}$ DP, Steinke DT, Williams LK, Austin R, Lafata JE, Divine $\mathrm{G}$ et al. Adherence analysis using visual analog scale versus claims-based estimation. Ann Pharmacother 2007; 41(11): 1792-1797.

41 Amico KR, Fisher WA, Cornman DH, Shuper PA, Redding CG, Konkle-Parker DJ et al. Visual analog scale of ART adherence: association with 3-day self-report and adherence barriers. J Acquir Immune Defic Syndr 2006; 42(4): 455-459.

42 Ivanova JI, Birnbaum HG, Hsieh M, Yu AP, Seal B, van der Molen T et al. Adherence to inhaled corticosteroid use and local adverse events in persistent asthma. Am J Manag Care 2008; 14(12): 801-809.

43 Zeller A, Ramseier E, Teagtmeyer A, Battegay E. Patients' self-reported adherence to cardiovascular medication using electronic monitors as comparators. Hypertens Res 2008; 31(11): 2037-2043.

44 The Eye Diseases Prevalence Research Group. Causes and prevalence of visual impairment among adults in the United States. Arch Ophthal 2004; 122: 477-485.

45 Ostermann J, Sloan FA, Herndon L, Lee PP. Racial differences in glaucoma care. the longitudinal pattern of care. Arch Ophthal 2005; 123: 1693-1698.

46 Mason RP, Kosoko O, Wilson MR, Martone JF, Cowan Jr CL, Gear JC et al. National survey of the prevalence and risk factors of glaucoma in St. Lucia, West Indies: Part 1: prevalence findings. Ophthalmology 1989; 96(9): 1363-1368.

47 Herndon LW, Brunner TM, Rollins JN. The Glaucoma Research Foundation Patient Survey: patient understanding of glaucoma and its treatment. Am J Ophthalmol 2006; 141: 22-28. 